\title{
Thermally activated martensite formation in ferrous alloys
}

\author{
Villa, Matteo; Somers, Marcel A. J.
}

\section{Published in:}

Scripta Materialia

Link to article, DOI:

10.1016/j.scriptamat.2017.08.024

Publication date:

2017

Document Version

Peer reviewed version

Link back to DTU Orbit

Citation (APA):

Villa, M., \& Somers, M. A. J. (2017). Thermally activated martensite formation in ferrous alloys. Scripta Materialia, 142, 46-49. https://doi.org/10.1016/j.scriptamat.2017.08.024

\section{General rights}

Copyright and moral rights for the publications made accessible in the public portal are retained by the authors and/or other copyright owners and it is a condition of accessing publications that users recognise and abide by the legal requirements associated with these rights.

- Users may download and print one copy of any publication from the public portal for the purpose of private study or research.

- You may not further distribute the material or use it for any profit-making activity or commercial gain

- You may freely distribute the URL identifying the publication in the public portal

If you believe that this document breaches copyright please contact us providing details, and we will remove access to the work immediately and investigate your claim 


\author{
Thermally activated martensite formation in ferrous alloys \\ Matteo Villa*, Marcel A.J. Somers \\ Technical University of Denmark, Department of Mechanical Engineering, \\ Produktionstorvet, Building 425, DK 2800 Kgs. Lyngby, DK \\ $\underline{\text { matv@mek.dtu.dk, }}$ somers@mek.dtu.dk
}

\begin{abstract}
Magnetometry was applied to investigate the formation of $\alpha / \alpha^{\prime}$ martensite in 13 ferrous alloys during immersion in boiling nitrogen and during re-heating to room temperature at controlled heating rates in the range $0.0083-0.83 \mathrm{~K} \mathrm{~s}^{-1}$. Data shows that in 3 of the alloys, those that form $\{557\}_{\gamma}$ martensite, no martensite develops during cooling. For all investigated alloys, irrespective of the type of martensite forming, thermally activated martensite develops during heating. The activation energy for thermally activated martensite formation is in the range $8-27 \mathrm{~kJ} \mathrm{~mol}^{-1}$ and increases with the fraction of interstitial solutes in the alloy.
\end{abstract}

Key words: martensitic phase transformations; steel; kinetics

Evidence of thermally activated, i.e. time dependent, martensite formation was firstly reported by Kurdjumov and Maximova [1] who showed an increase in magnetization during isothermal holding of Fe-based alloys at cryogenic temperatures as well as during continuous heating from $77 \mathrm{~K}$.

The authors interpreted the kinetics of transformation in terms of time-dependent

* corresponding author; Tel: +45 45252221; Fax: 45251961 
nucleation and growth of martensite and obtained an activation energy for timedependent martensite formation, $E_{A}$, equal to $7 \mathrm{~kJ} \mathrm{~mol}^{-1}$ by applying an Arrhenius type analysis. $E_{A}$ was conceived as the sum of two terms (see Ref. [2]): a temperaturedependent activation energy for nucleation and a constant activation energy for growth.

Thermally-activated growth of martensite implies that at a sufficiently low temperature, say lower than $77 \mathrm{~K}$, the transformation cannot progress at an experimentally observable rate, i.e. infinitely slow. Kulin and Cohen showed as early as 1950 that this is not the case, and martensite formation can easily occur at a temperature as low as the boiling point of Helium [3], $4 \mathrm{~K}$. Additionally, Bunshah and Mehl [4] firstly demonstrated in 1953 that at $77 \mathrm{~K}$ the formation of several units of martensite can take place within $1 \mu$ s and that the growth rate of the units can be independent of temperature within a significantly large temperature interval (i.e. growth is athermal).

Based on these early observations, Cohen and co-workers developed a nucleationcontrolled description of the kinetics of martensite formation, where nucleation of martensite is time dependent and growth is instantaneous. Moreover, beyond a certain threshold value of the driving force for transformation, $\Delta G^{*}$, nucleation of martensite is considered not suppressible [5].

In the following 60 years, Cohen's approach has been declined in different forms (see Refs. [6,7]). The transformation has been studied at the onset of the process and $E_{A}$ has been evaluated from the time necessary to reach a fixed (small) fraction of martensite, say $0.2 \%$, in a series of isothermal tests conducted for $\Delta G<\Delta G^{*}$ (where $\Delta G$ is the driving force for transformation). According to this approach, $E_{A}$ is proportional to the energy barrier for nucleation of the most potent nuclei in the material and is a linear function of $\Delta G$. 
(Table 1), including a re-evaluation of those from previous work [14]. The formation of martensite was monitored applying magnetometry, implying that only ferromagnetic $\alpha / \alpha^{\prime}$ martensite is revealed; paramagnetic $\varepsilon$ martensite, if any, remains unobserved. Details on material preparation, experimental setup and quantitative phase analysis were reported earlier [13-15].

Table 1. Sample geometries, austenitization treatment and alloying (in wt-\%) of the 13 ferrous alloys. Sample geometry is expressed as either diameter of disks $\varnothing$ or diagonal of square plates $D$ (in $\mathrm{mm}$ ) / thickness (in $\mathrm{mm}$ ). Austenitization conditions are expressed as temperature (in K) / time (in ks).

\begin{tabular}{|c|c|c|c|c|c|c|c|c|c|c|c|c|}
\hline Alloy & Geometry & Austenitization & $\mathbf{N}$ & $\mathbf{C}$ & $\mathbf{C r}$ & $\mathbf{N i}$ & $\mathbf{M n}$ & $\mathbf{S i}$ & $\mathbf{M o}$ & $\mathbf{C u}$ & $\mathbf{T i}$ & $\mathbf{A l}$ \\
\hline $2.2 \mathrm{~N}$ & $\mathrm{D} 3 / 0.025$ & $923 / 1.8$ & 2.2 & - & - & - & - & - & - & - & - & - \\
\hline $1.8 \mathrm{~N}$ & $\mathrm{D} 3 / 0.025$ & $923 / 1.8$ & 1.8 & - & - & - & - & - & - & - & - & - \\
\hline $1.6 \mathrm{C}$ & $\varnothing 3 / 0.7$ & $1353 / 0.18$ & - & 1.59 & - & - & - & - & - & - & - & - \\
\hline $1.2 \mathrm{C}$ & $\varnothing 3 / 0.7$ & $1353 / 0.18$ & - & 1.20 & - & - & - & - & - & - & - & - \\
\hline $1 \mathrm{C}$ & $\varnothing 3 / 0.7$ & $1353 / 0.18$ & - & 0.97 & - & - & - & - & - & - & - & - \\
\hline $100 \mathrm{Cr} 6$ & $\varnothing 3 / 0.7$ & $1353 / 0.18$ & - & 0.96 & 1.6 & 0.1 & 0.1 & 0.3 & - & 0.2 & - & - \\
\hline $12 \mathrm{Cr}-0.7 \mathrm{C}$ & $\varnothing 2.2 / 0.7$ & $1453 / 0.3$ & - & 0.67 & 11.5 & - & 1.0 & 0.6 & - & 0.2 & - & - \\
\hline $17 \mathrm{Cr}-0.4 \mathrm{C}$ & $\varnothing 3 / 0.7$ & $1453 / 0.3$ & - & 0.38 & 17.0 & 2.1 & 0.5 & 0.5 & 0.1 & 0.4 & - & 0.2 \\
\hline $17 \mathrm{Cr}-0.2 \mathrm{C}$ & $\varnothing 3 / 0.7$ & $1453 / 0.3$ & - & 0.19 & 17.0 & 2.1 & 0.5 & 0.5 & 0.1 & 0.4 & - & 0.2 \\
\hline $15-7 \mathrm{PH}$ & $\mathrm{D} 3 / 0.25$ & $1253 / 0.3$ & - & 0.09 & 15.5 & 7.1 & 0.6 & 0.8 & 2.1 & 0.4 & - & 1.2 \\
\hline $17-7 \mathrm{PH}$ & $\mathrm{D} 3 / 0.15$ & $1253 / 0.3$ & - & 0.08 & 17.0 & 7.0 & 0.5 & 0.6 & - & 0.3 & - & 1.1 \\
\hline $12 \mathrm{Cr}-9 \mathrm{Ni}$ & $\mathrm{D} 3 / 0.7$ & $1453 / 0.3$ & - & 0.02 & 12.0 & 8.6 & 0.3 & 0.4 & 3.5 & 1.9 & 0.9 & 0.4 \\
\hline $15 \mathrm{Cr}-13 \mathrm{Ni}$ & $\varnothing 3 / 1$ & $1323 / 1.8$ & - & $<0.001$ & 15.3 & 12.7 & - & - & - & - & - & - \\
\hline
\end{tabular}

The investigations consisted of two types of tests: ex situ tests and in situ tests. The ex situ tests consisted of measuring the magnetization of the samples prior to sub-zero Celsius treatment and after additional immersion in boiling nitrogen and (up-quenching) in water. In the in situ tests, the magnetization of the samples was measured straight after immersion in boiling nitrogen, at approx. $80 \mathrm{~K}$, and thereafter monitored during isochronal heating to $280 \mathrm{~K}$. With the exception of $15 \mathrm{Cr}-13 \mathrm{Ni}$, the applied heating rates were in the range $0.0083-0.167 \mathrm{~K} \mathrm{~s}^{-1}$. The $15 \mathrm{Cr}-13 \mathrm{Ni}$ alloy was heated at rates in the 
range $0.05-0.83 \mathrm{~K} \mathrm{~s}^{-1}$ to elucidate the initial acceleration of the transformation on continuous heating (see below). Results are presented in Table 2 and Fig. 1.

Table 2. Molar fraction of $\alpha / \alpha^{\prime}$ martensite $f$ versus thermal step: $R T$ refers to the material after cooling to room temperature; $B N$ after additional immersion in boiling nitrogen; $B N-W$ after additional immersion in boiling nitrogen and re-heating in water; BN-RH after additional immersion in boiling nitrogen and controlled re-heating at the slowest applied rate. $\Delta f_{M A X}$ is the additional fraction of martensite formed during heating measured at the maximum of the transformation rate. For 15-7PH, metallography indicated the presence of approx. $10 \% \delta$-Fe, which is included in the calculation of $f$.

\begin{tabular}{|c|c|c|c|c|c|c|c|}
\hline Alloy & Group & Type of martensite & $\boldsymbol{f}_{\boldsymbol{R T}}$ & $\boldsymbol{f}_{\boldsymbol{B N}}$ & $\boldsymbol{f}_{\boldsymbol{B N}-\boldsymbol{W}}$ & $\boldsymbol{f}_{\boldsymbol{B N}-\boldsymbol{R H}}$ & $\Delta \boldsymbol{f}_{\boldsymbol{M A X}}$ \\
\hline $2.2 \mathrm{~N}$ & I & $\{259\} \gamma$ & $1 \%$ & $35 \%$ & $38 \%$ & $52 \%$ & $8.5 \%$ \\
\hline $1.8 \mathrm{~N}$ & I & $\{259\} \gamma$ & $32 \%$ & $53 \%$ & $62 \%$ & $77 \%$ & $8.0 \%$ \\
\hline $1.6 \mathrm{C}$ & I & $\{225\} \gamma+\{259\} \gamma$ & $57 \%$ & $85 \%$ & $86 \%$ & $90 \%$ & $1.4 \%$ \\
\hline $1.2 \mathrm{C}$ & I & $\{225\} \gamma$ & $81 \%$ & $94 \%$ & $94 \%$ & $97 \%$ & $1.0 \%$ \\
\hline $1 \mathrm{C}$ & I & $\{225\} \gamma$ & $89 \%$ & $94 \%$ & $95 \%$ & $98 \%$ & $1.5 \%$ \\
\hline $100 \mathrm{Cr} 6$ & I & $\{225\} \gamma+\{259\} \gamma$ & $59 \%$ & $79 \%$ & $80 \%$ & $86 \%$ & $1.6 \%$ \\
\hline $12 \mathrm{Cr}-0.7 \mathrm{C}$ & I & $\{225\} \gamma$ & $5 \%$ & $64 \%$ & $66 \%$ & $77 \%$ & $3.3 \%$ \\
\hline $17 \mathrm{Cr}-0.4 \mathrm{C}$ & I & $\{259\} \gamma$ & $1 \%$ & $34 \%$ & $37 \%$ & $63 \%$ & $6.7 \%$ \\
\hline $17 \mathrm{Cr}-0.2 \mathrm{C}$ & I & $\{557\} \gamma+\{259\} \gamma$ & $16 \%$ & $55 \%$ & $64 \%$ & $78 \%$ & $5.9 \%$ \\
\hline $15-7 \mathrm{PH}$ & II & $\{557\} \gamma$ & $13 \%$ & $13 \%$ & $15 \%$ & $99 \%$ & - \\
\hline $17-7 \mathrm{PH}$ & II & $\{557\} \gamma$ & $7 \%$ & $7 \%$ & $12 \%$ & $93 \%$ & - \\
\hline $12 \mathrm{Cr}-9 \mathrm{Ni}$ & II & $\{557\} \gamma$ & $79 \%$ & $79 \%$ & $79 \%$ & $91 \%$ & - \\
\hline $15 \mathrm{Cr}-13 \mathrm{Ni}$ & I & $\{112\} \gamma$ & - & $21 \%$ & $21 \%$ & $27 \%$ & $1.1 \%$ \\
\hline
\end{tabular}

Table 2 shows that all the alloys under investigation, except for $15 \mathrm{Cr}-13 \mathrm{Ni}$, are partly martensitic after cooling to room temperature (column $f_{R T}$ ). Additional formation of martensite can be promoted at sub-zero Celsius temperatures. From a kinetics point of view, alloys can be classified into two groups, labelled I and II, respectively. For all alloys of group I, immersion in boiling nitrogen promotes instantaneous formation of martensite (compare columns $f_{R T}$ and $f_{B N}$ ); for the alloys of group II no (additional) 
martensite forms during cooling.

Strikingly, in all investigated alloys and steels martensite formation is observed during (re-)heating (compare columns $f_{B N}$ and $f_{B N-W}, f_{N B N-R H}$ ) irrespective of whether no or abundant martensite had formed during cooling to $77 \mathrm{~K}$. The amount of martensite formed during heating is consistently highest for the slowest heating rate (compare columns $f_{B N-W}$ and $\left.f_{N B N-R H}\right)$.

Fig. 1 shows that, with the exception of $15 \mathrm{Cr}-13 \mathrm{Ni}$, the transformation on heating starts slowly, accelerates with increasing temperature, and finally slows down before reaching $280 \mathrm{~K}$. In $15 \mathrm{Cr}-13 \mathrm{Ni}$ the transformation shows two distinct accelerations, maybe in connection with the occurrence of two overlapping transformation processes like, for example, the conversion of $\varepsilon$ martensite into $\alpha$ and the direct formation of $\alpha$ martensite from austenite.

Consistent for all alloys investigated, the transformation curves are shifted towards higher temperatures on faster heating. This is clear evidence that martensite formation during heating is thermally activated.

The activation energy $E_{A}$ of the thermally activated mechanism that governs the rate of the transformation can be determined with a Kissinger-like analysis, where $\ln \left(T_{f^{\prime}}{ }^{2} /\right.$ $\phi$ ) depends linearly on $1 / T_{f^{\prime}}$ and the slope equals $E_{A} / R$. Here, $T_{f^{\prime}}$ is the temperature corresponding to a fixed stage of transformation, $f^{\prime}$, and $\phi$ is the heating rate (cf. Ref. [16]); $f^{\prime}$ is interpreted as the fraction of martensite developed during re-heating $\Delta f$.

$E_{A}$ was evaluated every increment in $\Delta f$ by 0.001 for the range $0.005 \leq \Delta f \leq$ $\Delta f_{M A X}$, where $\Delta f_{M A X}$ applies at the maximum transformation rate. For each of the alloys of group I, the maximum transformation rate occured at a fixed transformed fraction, while for the alloys of group II, $\Delta f_{M A X}$ is a function of the heating rate. In this case, the 
minimum value of $\Delta f_{M A X}$, which is reported for the fastest applied heating of $0.167 \mathrm{~K} \mathrm{~s}^{-}$ ${ }^{1}$, was used. The interval for $\Delta f$ was chosen to secure sufficient experimental accuracy and to ensure that the analysis is applied sufficiently far from equilibrium [17]. The following additional criteria for validity were taken: the linear regression coefficient obtained for the linear dependence of $\ln \left(T_{f^{\prime}}{ }^{2} / \phi\right)$ on $1 / T_{f^{\prime}}$ should be better than 0.9 ; the isochronal cycle should have ran for at least $60 \mathrm{~s}$. These criteria ensure that a linear fit of data is realistic and that the heating rate experienced by the sample corresponds to the set heating rate, respectively. Our earlier results presented in Ref. [14] were re-evaluated according to these criteria.

All evaluated activation energies meeting the above criteria are collected in Fig. 2 versus the atomic fraction of interstitials. The data is presented such that the error bars in $E_{A}$ are given as the minimum, maximum and average values taking into account the standard error of the estimate for linear regression. With the exception of the Fe- $\mathrm{N}$ alloys, the $\mathrm{N}$-content was assumed negligible.

Fig. 2 shows that $E_{A}$ ranges from 8 to $27 \mathrm{~kJ} \mathrm{~mol}^{-1}$. There is a general trend that $E_{A}$ increases with the total fraction of interstitial solutes. The same trend is visible when each group of alloys per set of materials is considered independently (i.e. 1C versus $1.2 \mathrm{C}$ versus $1.6 \mathrm{C}, 17 \mathrm{Cr}-0.2 \mathrm{C}$ versus $17 \mathrm{Cr}-0.4 \mathrm{C}$ and $1.8 \mathrm{~N}$ versus $2.2 \mathrm{~N})$. Unequivocally, the experiments show that the presence of interstitial solutes increases the activation energy for martensite formation.

Ferrous $\alpha$ martensites are classified as $\left\{\begin{array}{llll}3 & 10 & 15\end{array}\right\}_{\gamma},\left\{\begin{array}{lll}2 & 5 & 9\end{array}\right\}_{\gamma},\left\{\begin{array}{llll}2 & 2 & 5\end{array}\right\}_{\gamma},\left\{\begin{array}{lll}1 & 1 & 2\end{array}\right\}_{\gamma}$ and $\begin{cases}5 \\ \text { a }\end{cases}$ $57\}_{\gamma}$ (see Refs. $[18,19]$ ). The types of martensite developing in the alloys under investigation was determined by metallography as indicated in Table 2 . 
Table 2 reveals that the steels/alloys classified as group II develop $\left\{\begin{array}{lll}5 & 5\end{array}\right\}_{\gamma}$ martensite. Evidently, the kinetics of formation of $\left\{\begin{array}{lll}5 & 5 & 7\end{array}\right\}_{\gamma}$ martensite differs from the kinetics of formation of all the other types of martensite (group I): the formation of $\left\{\begin{array}{lll}5 & 5 & 7\end{array}\right\}_{\gamma}$ martensite on cooling is suppressed by immersion in boiling nitrogen, whereas the formation of all the other types of martensite is not.

In 1940 [20], Foerster and Scheil suggested that martensite formation can take place according to two distinct mechanisms, Schiebung and Umklapp. The progress of Umklapp martensite was claimed instantaneous, contrary to time-dependent growth of Schiebung martensite units. Experimental evidence consisted in the observation of sudden changes in the electrical properties of the material during the formation of Umklapp martensite, and not during the formation of Schiebung martensite. Consistently, in 1958 [21], Honma showed firstly that the formation of Umklapp martensite yields acoustic emission, whereas the formation of Schiebung martensite does not.

Thereafter, in 1966 [22], Huizing and Klostermann anticipated that $\left\{\begin{array}{lll}5 & 5 & 7\end{array}\right\}$ martensite, internally slipped $\left\{\begin{array}{lllll}2 & 2 & 5\end{array}\right\}_{\gamma}$ martensite and the slipped part of $\left\{\begin{array}{lll}2 & 5 & 9\end{array}\right\}_{\gamma}$ martensite are morphologically different types of martensite formed by the same mechanism (i.e. Schiebung martensite). Consistently, Sadovskii and Romashev showed in 1978 that the growth of slipped martensite on twinned martensite in the $\left\{\begin{array}{ll}25 & 9\end{array}\right\}_{\gamma}$ system at $77 \mathrm{~K}$ is time-dependent [23].

To our best knowledge, it is now established for all types of martensite but $\left\{\begin{array}{lll}5 & 5 & 7\end{array}\right\}_{\gamma}$ that transformation events can take place within a small fraction of a second, indicating instantaneous growth [24-29]. Additionally, it has been shown for all types of martensite

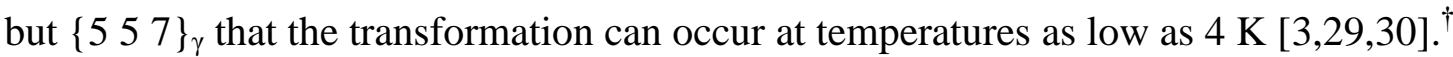

\footnotetext{
${ }^{\dagger}$ It is explicitly mentioned that, within our interpretation, strain-induced martensite is classified as $\{11$ $2\} \gamma$.
} 
Evidently, the kinetics of transformation can be rationalized providing that the formation of Schiebung martensite, which corresponds to $\left\{\begin{array}{lll}5 & 5\end{array}\right\}_{\gamma}$ and to a slipped product growing on $\left\{\begin{array}{llll}2 & 5 & 9\end{array}\right\}_{\gamma}$ and $\left\{\begin{array}{llll}2 & 2 & 5\end{array}\right\}_{\gamma}$, is thermally activated and thereby suppressible, while the formation of Umklapp martensite is athermal and thereby insuppressible. This is consistent with the possibility to suppress martensite formation at high temperature (cf. Refs. [10-12]).

Based on the above rationalization, $E_{A}$ determined in our work is the activation energy for the formation of Schiebung martensite. Fig. 2 indicates that $E_{A}$ lies in the range $8-27 \mathrm{~kJ} \mathrm{~mol}^{-1}$ and increases with the fraction of interstitials. It is well known that small fractions of $\mathrm{C}$ atoms can suppress the formation of Schiebung martensite in Fe-Ni alloys [31-33]. Additionally, it has been established that the critical cooling rate to

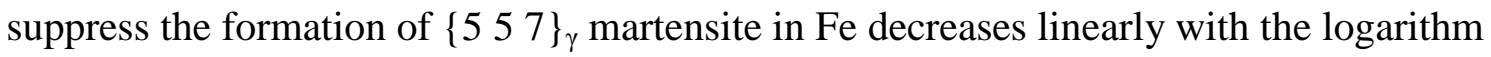
of the fraction of $\mathrm{C}$ atoms [12]. Since small differences in $\mathrm{C}$ (and N) content do not significantly affect $\Delta G$, as demonstrated by an invariant $M_{S}$, it is anticipated that $E_{A}$ obeys a similar logarithmic dependence on the fraction of interstitials (Fig. 2b).

In a molecular dynamics study [34], Bos et al. studied the movement of the b.c.c../f.c.c. interface in $\mathrm{Fe}$ and obtained an effective activation energy of $6 \mathrm{~kJ} \mathrm{~mol}^{-1}$ for the movement of a martensite/austenite interface. Surprisingly, this value is consistent with extrapolation of data in Fig. $2 b$ to a very low content of interstitials. Borgenstam and Hillert treated martensitic transformations as a common chemical reaction and estimated $E_{A}$ to $7 \mathrm{~kJ} \mathrm{~mol}^{-1}$ for $\mathrm{Fe}-\mathrm{Ni}-\mathrm{Mn}$ and $\mathrm{Fe}-\mathrm{Cr}-\mathrm{Ni}$ alloys forming martensite isothermally at cryogenic temperatures [35]. This value is also consistent with data in Fig. 2b.

At present, there is insufficient information to conclude about the rate-controlling 
mechanism for Schiebung martensite. Fascinating is the possibility that Schiebung martensite is the product of a transformation that is not strictly martensitic [36]. For martensitic transformations the austenite/martensite interface is (presumed) glissile. Unequivocal evidence for a glissile interface is the formation of martensite at $4 \mathrm{~K}$ [37,38]. To our best knowledge, martensite formation at $4 \mathrm{~K}$ has hitherto not been demonstrated for $\left\{\begin{array}{l}5 \\ 5\end{array} 7\right\} \gamma$ martensite. Maki and co-workers recently claimed that the austenite/martensite interface for $\left\{\begin{array}{l}557 \\ 7\end{array}\right\}_{\gamma}$ and for internally slipped $\{259\}_{\gamma}$ is sessile $[39,40]$. A sessile interface cannot move conservatively, implying that its movement is thermally activated. In this sense, the movement of the interface could be the ratedetermining mechanism for the formation of Schiebung martensite and inhibit its development at $4 \mathrm{~K}$.

To summarize, the present investigation shows that ferrous alloys and steel can be classified into two kinetic groups: in alloys of group I, martensite forms during immersion in boiling nitrogen; in alloys of group II, the formation of martensite on cooling in boiling nitrogen is suppressed. In both cases, martensite can form on reheating to room temperature.

There is a relationship between the transformation kinetics and the features of the developing martensite: twinned martensite and slipped martensite formed along $\left\{\begin{array}{llll}1 & 1 & 1\end{array}\right\}_{\gamma}$ shear bands (including strain-induced) correspond to kinetics group I; $\left.\begin{array}{lll}5 & 5 & 7\end{array}\right\}_{\gamma}$ martensite to kinetics group II.

All experimental observations can be rationalized considering that two distinct types of martensite exist: Schiebung martensite, which is suppressible and cannot form at $4 \mathrm{~K}$, and Umklapp martensite, which is un-suppressible and does form at temperature 
approaching absolute zero.

The activation energy for the formation of Schiebung martensite increases with the fraction of interstitials and for the investigated alloys ranges from approx. $8 \mathrm{~kJ} \mathrm{~mol}^{-1}$ to $27 \mathrm{~kJ} \mathrm{~mol}^{-1}$.

This work was financially supported by the Danish Council for Independent Research [grant number: DFF-4005-00223]. Eric J. Mittemeijer, Max Planck Institute for intelligent systems, Stuttgart, DE, is acknowledged for fruitful discussion in an early stage of this work and for supplying the Fe-C and the Fe-15Cr-13Ni alloys.

\section{References}

[1] G.V. Kurdjumov and O.P. Maksimova, Dokl Akad Nauk SSSR, 61.1 (1948), 83-86.

[2] B.S. Lement, Il Nuovo Cimento, 1.S4 (1955), 295-322.

[3] S.A. Kulin and M. Cohen. Trans. AIME, 188.9 (1950), 1139-1143.

[4] R.F. Bunshah, R.F. Mehl. Trans. AIME, 197.9 (1953), 1251-1258.

[5] M. Cohen, Trans. AIME 212.2 (1958), 171-183.

[6] N.N. Thadhani, M.A. Meyers, "Prog. Mater. Sci. 30 (1986) 1-37.

[7] A. Borgenstam, M Hillert, Acta Mater. 48:11 (2000) 2777-2785.

[8] T. Kakeshita, K. Kuroiwa, K. Shimizu, T. Ikeda, A. Yamagishi, M. Date, Mater. Trans. Jim 34.5 (1993) 423-428.

[9] A.N. Holden, Acta Metall., 1.1 (1953), 617-623

[10]E.A. Wilson, ISIJ Int. 34:8 (1994) 615-630.

[11]D. A. Mirzayev, M.M. Shteynberg, T. N. Ponomareva, V.M. Schastlivtsev, Phys. Met. Metallogr. 47:1 (1979) 102-111. 
[12]D. A. Mirzayev, M.M. Shteynberg, T. N. Ponomareva, V.M. Schastlivtsev, Phys. Met. Metallogr. 47:5 (1979) 73-79.

[13] M. Villa, H.F. Hansen, M.A.J. Somers, "Martensite formation in Fe-C alloys at cryogenic temperatures“, submitted for publication

[14] M. Villa, T. Christiansen, M.F. Hansen, M. AJ Somers, Metall. Ita., 11:12 (2015) $39-46$.

[15]M. Villa, M.F. Hansen, K. Pantleon, M.A.J. Somers, Mater. Sci. Technol., 31:11 (2015) 1355-1361.

[16]E.J. Mittemeijer, J. Mater Sci, 27:15 (1992) 3977-3987.

[17]W. Baumann, A. Leineweber, E.J. Mittemeijer, J. Mater. Sci. 45 (2010) 6075-6082.

[18]P.G. McDougall, C.M. Wayman, The crystallography and morphology of ferrous martensites, in: Martensite - A tribute to Morris Cohen, (Eds.) G.B. Olson, W.S. Owen, ASM International, Cleveland, 1992, pp. 59-96

[19]T. Maki, Morphology and Substructure of Martensite in Steels, in: Phase Transformations in Steels 2, E. Pereloma and D.V. Edmonds (Eds.), 2012, pp. 3458.

[20]F. Foerster, E. Scheil, Ztsch. Metallkunde 32:6 (1940) 165-173.

[21]T. Honma, DENKI-SEIKO 29:4 (1958) 261-276.

[22]R. Huizing, J.A. Klostermann, Acta Metall. 14:12 (1966) 1693-1702.

[23] V.D. Sadovskii, L. N. Romashev, Soviet Physics - Doklady 23:1 (1978) 77-79.

[24] G.R. Speich, A.J. Schwoeble, Acoustic emission during phase transformation in steel, in: Monitoring Structural Integrity by Acoustic Emission ASTM-SPT571, 1975, pp. 40-58. 
[25] Y. Sano, S.N. Chang, M.A. Meyers, S. Nemat-nasser, Acta Metall. Mater., 40.2 (1992) 413-417.

[26] S.N. Chang, M. A. Meyers. Acta Metall. 36.4 (1988) 1085-1098

[27] M.A. Meyers, J. R. C. Guimaraes, Mater. Sci. Eng. 24.2 (1976) 289-292.

[28] K. Takashima, Y. Higo, S. Nunomura, Philos. Mag. A 49:2 (1984) 231-241.

[29] T. Kakehita, T. Saburi, K. Kindo, S. Endo, Phase Trans. 70:2 (1999) 65-113.

[30] R.P. Reed, The plate-like martensite transformation in Fe-Ni alloys, Acta Metal. 15 (1967) 1287-1296.

[31]R.B.G. Yeo, ASM Trans. Quarterly 57:1 (1964) 48-61.

[32]C. Crussard, J. Philibert, Revue De Metallurgie 53:12 (1956) 973-980.

[33] V. Raghavan, M. Cohen, Metall. Trans. 2:9 (1971) 2409-18.

[34]C. Bos, J. Sietsma, B.J. Thijsse, Physical Review B 73:10 (2006) 104117.

[35]A. Borgenstam, M. Hillert, Acta Mater. 45:2 (1997) 651-662.

[36]D.A. Mirzayev, M.M. Shteynberg, T. N. Ponomareva, B. Ya. Bylskiy, S. Ye Karzunov, Phys. Met. Metallogr. 51:2 (1981) 116-127.

[37]F. J. Schoen, W. S. Owen, Scripta Metall. 5:4 (1971) 315-317.

[38]H.K.D.H. Bhadeshia, C.M. Wayman, Phase Transformations: Nondiffusive. In: D. Laughlin and K. Hono (Eds.) Physical 706 Metallurgy, 5th edn, vol I, Ch. 9, 10211072 (Elsevier, 2014).

[39]A. Shibata, T. Furuhara, T. Maki, Acta Mater. 58 (2010) 3477-3492.

[40] T. Moritami, N. Miyajima, T. Furuhara, T. Maki, Scripta Mater. 47 (2002) 193-199. 

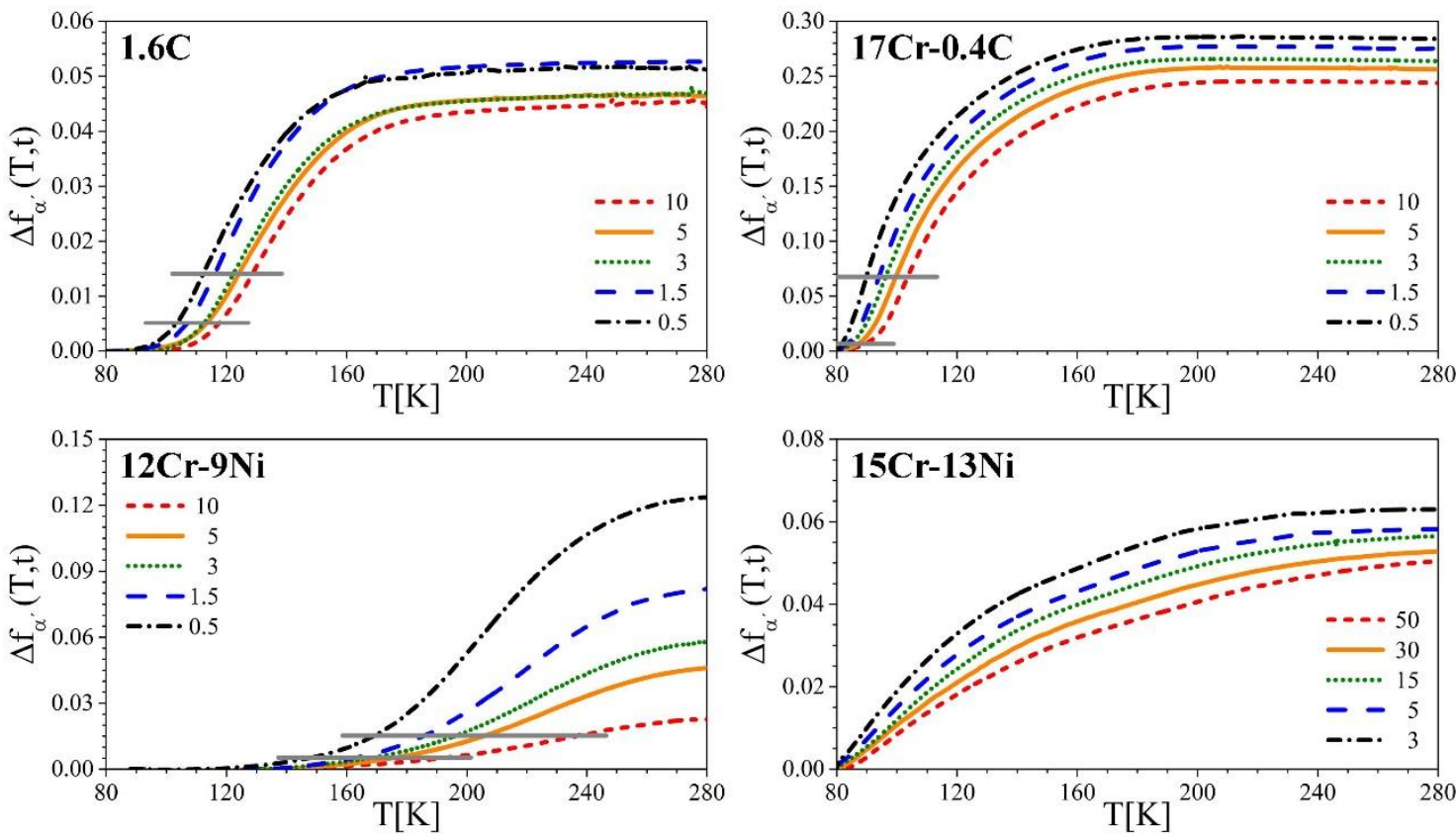

Fig.1 Examples of martensite formation during isochronal heating from $80 \mathrm{~K}$ : fraction of martensite, $\Delta f$, plotted versus temperature, T. Numbers in the legend refer to the heating rate applied, $\phi$, expressed in $\mathrm{K} \mathrm{min}^{-1}$. The grey horizontal lines indicate the intervals used to calculate $\mathrm{E}_{\mathrm{A}}$. Data for $1.6 \mathrm{C}$ and $17 \mathrm{Cr}-0.4 \mathrm{C}$ are chosen as representative for the Fe-C alloys and the Fe-Cr-C steels, respectively. Data referring to the Fe-N alloys, to $100 \mathrm{Cr} 6$ and to the PH steels were presented earlier [14].
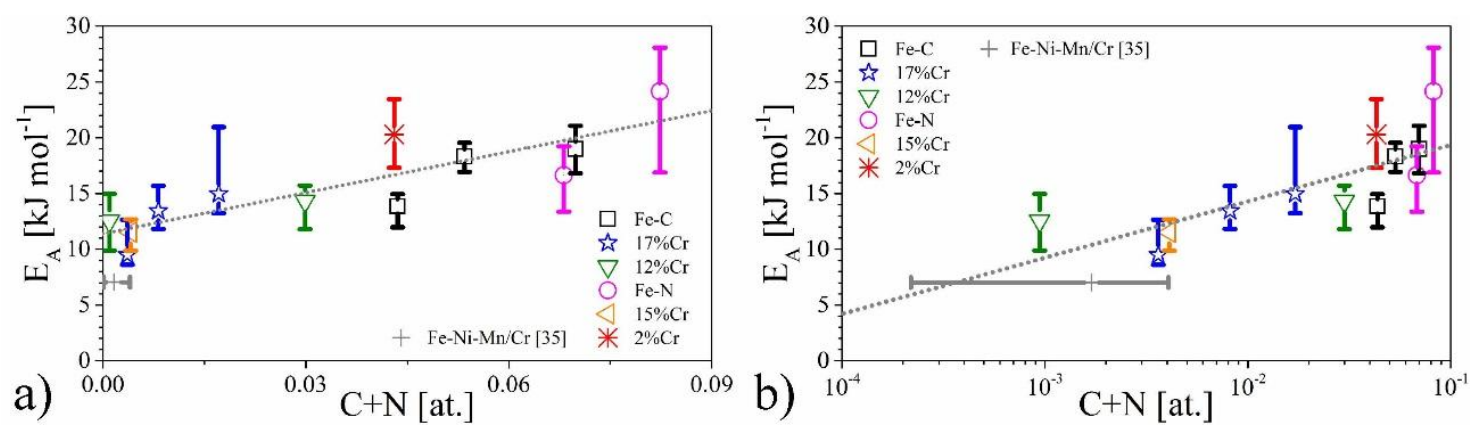

Fig.2 Activation energy for thermally activated martensite formation $\mathrm{E}_{\mathrm{A}}$ plotted versus the atomic fraction of interstitial solutes in the material, $\mathrm{C}+\mathrm{N}$, expressed in (a) linear scale and (b) logarithmic scale. 

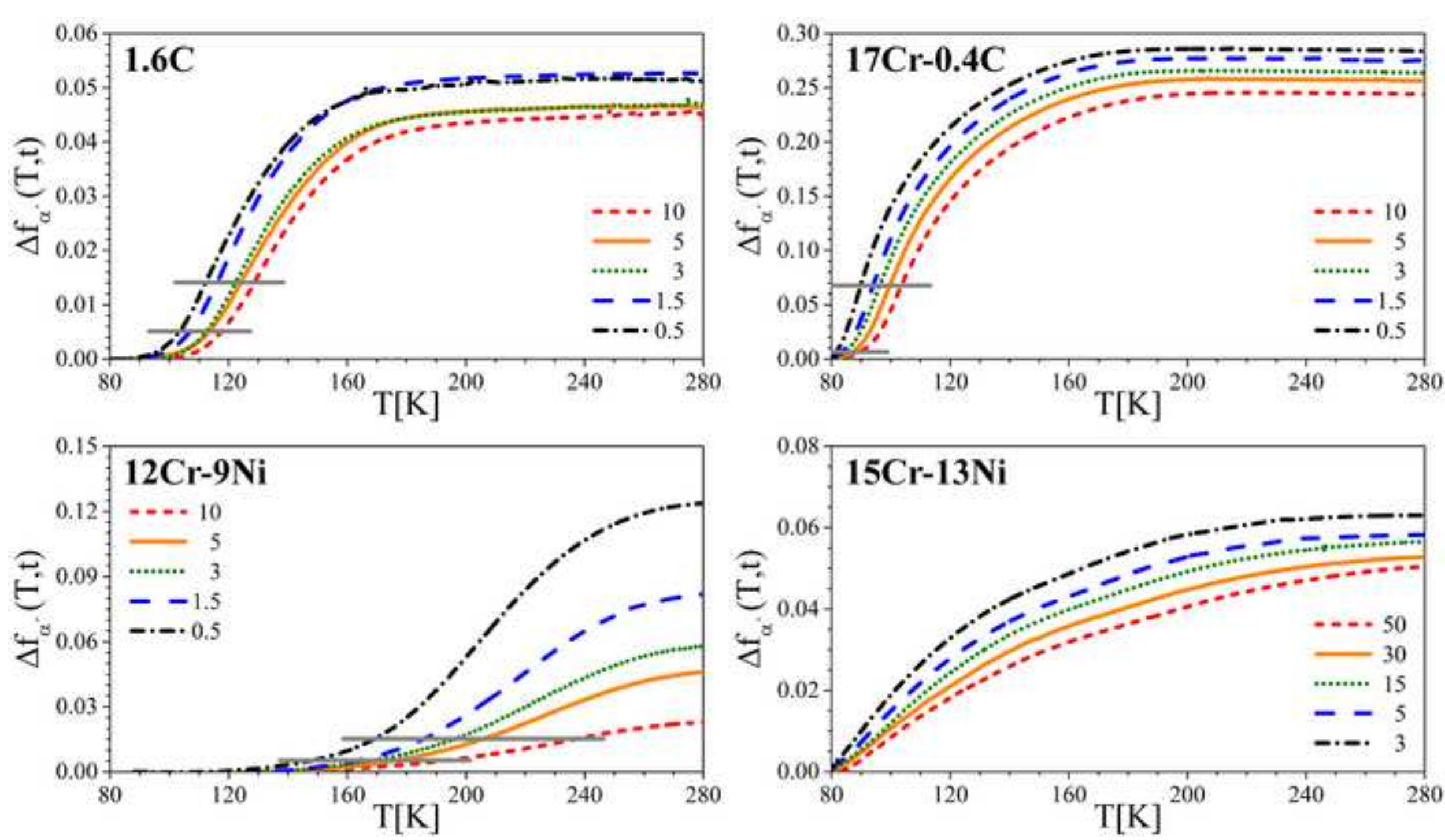

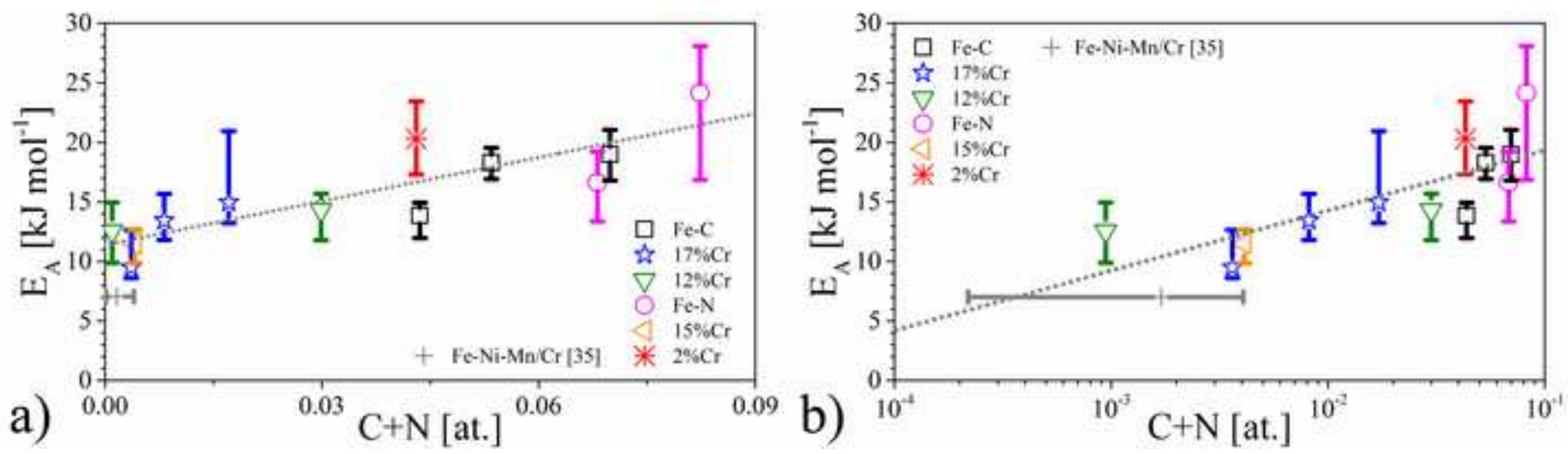